\title{
Kinetics of the Oxidation of Bromopyrogallol Red by Nitrite Ion in Aqueous Acidic Medium
}

\author{
${ }^{*}$ S. O. Idris ${ }^{1}$, V. O. Samson ${ }^{1}$ and B. Myek ${ }^{2}$ \\ ${ }^{1}$ Department of Chemistry, Ahmadu Bello University, Zaria, Nigeria \\ 2Department of Basic Research, National Research Institute for Chemical Technology, Zaria, \\ Nigeria
}

Keywords: Kinetics, Nitrite, Mechanism, Bromopyrogallol red.

Abstract. The kinetics of the electron transfer reaction between Bromopyrogallol $\left(\mathrm{BPR}^{2-}\right)$ and nitrite ion in aqueous acidic solution has been studied in the acid range $0.1 \times 10^{-4} \leq[\mathrm{H}+] \leq 2 \times 10^{-4}$ mol dm${ }^{-3}$, ionic strength $0.01 \leq[\mathrm{I}] \leq 0.18 \mathrm{~mol} \mathrm{dm}^{-3}(\mathrm{NaCl})$ and $\mathrm{T}=29 \pm 1 .{ }^{\circ} \mathrm{C}$. The reaction shows a first order dependence on oxidant and reductant concentration respectively. The rate of the reaction increases with increase in $\left[\mathrm{H}^{+}\right]$. Plot of $\mathrm{k}_{2}$ versus $\left[\mathrm{H}^{+}\right]$was linear with a positive intercept. The overall reaction conforms to the rate law:

$$
-\mathrm{d}\left[\mathrm{BPR}^{2-}\right] / \mathrm{dt}=\left(\mathrm{a}+\mathrm{b}\left[\mathrm{H}^{+}\right]\right)\left[\mathrm{BPR}^{2-}\right]\left[\mathrm{NO}_{2}{ }^{-}\right]
$$

The stoichiometry of the reaction is $1: 1\left(\mathrm{BPR}^{2-}: \mathrm{NO}_{2}^{-}\right)$. Added anions had no effect on the rate of the reaction. The results of spectroscopic investigation indicate that no intermediate complex is probably formed in the course of this reaction. The reaction is believed to proceed via the outersphere mechanistic pathway.

\section{Introduction}

Oxidation-reduction reaction involving nitrite ion $\left(\mathrm{NO}_{2}^{-}\right)$is well known. The studied of reduction of $\mathrm{Pt}\left[\mathrm{Co} \text {-phenylene-bis-dimethylarsin } \mathrm{Br}_{2}\right]^{2+}$ by $\mathrm{NO}_{2}{ }^{-}$in anhydrous $\mathrm{MeOH}$ has been reported. It was found that the reaction proceeded through a two steps inner-sphere mechanism which involves the transfer of two electrons from the reductant to the oxidant. In the reduction of riboflavine by $\mathrm{NO}_{2}^{-}$, $\mathrm{H}_{2} \mathrm{O}_{2}$ was obtained as the product while $\mathrm{NH}_{3}$ was the product formed for the reaction involving ascorbic acid [1].

Bromopyrogallol red is of immense important because of its wide range of uses as a metal indicator for the chelatometric titration of $\mathrm{Bi}, \mathrm{Co}(\mathrm{II}), \mathrm{Ni}$ and $\mathrm{Pb}$ as photometric reagents for various heavy metals and for indirect determination of anion such as halides and cyanides [2].

In spite of these and numerous other uses, redox Chemistry of this dye with NO2- has not been reported.

The present study is therefore undertaken to obtain kinetic data with a view of gaining insight into the mechanistic pathway of this redox reaction.

\section{Materials and Methods}

The chemicals used were of analytical grade and were used without further purification. Standard solution of bromopyrogallol red was prepared by dissolving accurate weight of bromopyrogallol red dye in a known volume of distilled water. Sodium nitrite solution was prepared by dissolving known quantities in distilled water. All other reagents used were of analytical grade.

The stoichiometry of the reaction was determined spectrophotometrically using the mole ratio method by keeping the concentration of the dye constant at $7.2 \times 10^{-5} \mathrm{~mol} \mathrm{dm}-3,\left[\mathrm{H}^{+}\right]=1.0 \times 10^{-4}$ $\mathrm{mol} \mathrm{dm}{ }^{-3}, \mathrm{I}=0.1 \mathrm{~mol} \mathrm{dm}^{-3}, \lambda \max =525 \mathrm{~nm}, \mathrm{~T}=29 \pm 1^{\circ} \mathrm{C}$ and $\left[\mathrm{NO}_{2}{ }^{-}\right]=(2.16-9.36) \times 10^{-3} \mathrm{~mol} \mathrm{dm}-$ 3. The stoichiometry was evaluated from the plot of absorbance versus [reductant]/ [oxidant] after the reaction had gone to completion by the observation of a steady zero absorbance value over a period of two days. 
A Corning Colorimeter Model 252 spectrophotometer was used to follow the decrease in absorbance of the dye at $525 \mathrm{~nm}$. The kinetic runs were conducted under pseudo - first order conditions with $\left[\mathrm{NO}_{2}^{-}\right]$in excess over bromopyrogallol red. Temperature, ionic strength and hydrogen ion concentration were maintained constant as: $\mathrm{T}=29 \pm 1{ }^{\circ} \mathrm{C}, \mathrm{I}=0.1 \mathrm{~mol} \mathrm{dm}-3(\mathrm{NaCl})$ and $\left[\mathrm{H}^{+}\right]=1.0 \times 10^{-4} \mathrm{~mol} \mathrm{dm}^{-3}\left(\mathrm{HNO}_{3}\right)$. The pseudo-first order plots of $\log \left(\mathrm{A}_{\mathrm{t}}-\mathrm{A}_{\infty}\right)$ versus time, were made (where $A_{t}$ and $A_{\infty}$ are the absorbance at time $t$ and at the end of the reaction respectively). From the slope of the plots, the pseudo-first order rate constant (k1) was determined [3].

The effect of hydrogen ion concentration on the rate of reaction was investigated by varying $[\mathrm{H}+]$ in the range $0.1 \times 10^{-4} \leq\left[\mathrm{H}^{+}\right] \leq 2 \times 10^{-4} \mathrm{~mol} \mathrm{dm}^{-3}$, while $\left[\mathrm{BPR}^{2-]}\right.$ and $\left[\mathrm{NO}_{2}^{-}\right]$were kept constant at $29 \pm 1^{\circ} \mathrm{C}$ and $\mathrm{I}=0.1 \mathrm{~mol} \mathrm{dm}^{-3}(\mathrm{NaCl})$.

The effect of ionic strength on the rate of the reaction was studied in the range $0.01 \leq[\mathrm{I}] \leq 0.18$ $\mathrm{mol} \mathrm{dm}{ }^{-3}(\mathrm{NaCl})$ while the concentration of $\left[\mathrm{H}^{+}\right]$and $\left[\mathrm{NO}_{2}-\right]$ were kept constant at $29 \pm 1^{\circ} \mathrm{C}$.

The effect of added anions were investigated by keeping the concentration of other reactants constant while varying the anions concentrations as follows: $\left[\mathrm{X}^{-}\right]=\left(10 \times 10^{-3}-400 \times 10^{-3}\right) \mathrm{mol} \mathrm{dm}^{-3}$, where $\mathrm{X}=\left(\mathrm{HCOO}^{-}\right.$and $\left.\mathrm{Cl}^{-}\right)$

\section{Results and Discussion}

The result of stoichiometry study for the oxidation of bromopyrogallol red by nitrite ion shows that one mole of $\mathrm{BPR}^{2-}$ consumed one mole of nitrite ion. Hence the overall equation for the reaction is shown in equation (1).

$$
\mathrm{BPR}^{2-}+\mathrm{NO}_{2}^{-}+\mathrm{H}^{+} \longrightarrow \text { product }
$$

Similar stoichiometry has been reported for the redox reactions of rosaniline monochloride and parafuchsin by nitrite ions respectively $[4-6]$.

Pseudo-first order plots of $\log (\mathrm{At}-\mathrm{A} \infty$ ) versus time were linear to more than $80 \%$ extent of the reaction. The linearity of the pseudo-first order plots to more than $80 \%$ suggests that the reaction is first order with respect to the bromopyrogallol red. The order of the reaction with respect to [NO2-] was also determined by plotting $\operatorname{logk} 1$ against $\log \left[\mathrm{NO}_{2}{ }^{-}\right]$(Fig.1). Slope of one was obtained which indicate that the order of reaction with respect to $\left[\mathrm{NO}_{2}^{-}\right]$is first order.

This reaction therefore conforms to the rate law:

$$
-\mathrm{d}\left[\mathrm{BPR}^{2-}\right] / \mathrm{dt}=\mathrm{k}_{2}\left[\mathrm{BPR}^{2-}\right]\left[\mathrm{NO}_{2}^{-}\right]
$$

Where $\mathrm{k}_{2}$ is the second order rate constant.

Effect of changes in ionic strength of the reaction medium indicated that change in ionic strength of the reaction medium did not alter the reaction rate (Table 1). This obeys a zero Bronsted Debye salt effect, implying that the activated complex is formed from charged and neutral molecule. This observation is consistent with equation (6) in the reaction mechanism.

The result in Table 1 shows that the rate of reaction increases with increase in $\left[\mathrm{H}^{+}\right]$in the range $0.1 \times 10^{-4} \leq\left[\mathrm{H}^{+}\right] \leq 2 \times 10^{-4} \mathrm{~mol} \mathrm{dm}{ }^{-3}$. Plot of logk1 versus $\log \left[\mathrm{H}^{+}\right]$gave a gradient of about unity, an indication that the order with respect to acid is first order. Also plot of $\mathrm{k}_{2}$ versus $\left[\mathrm{H}^{+}\right]$was linear with an intercept conforming with equation (3).

$$
\mathrm{k}_{2}=\mathrm{a}+\mathrm{b}\left[\mathrm{H}^{+}\right]
$$

The acid dependence of this nature shows that there is a rapid pre-equilibrium between the protonated and non-protonated forms in which both forms are reactive [7].

The overall rate equation in the acid range investigated is given as:

$$
-\mathrm{d}\left[\mathrm{BPR}^{2-}\right] / \mathrm{dt}=\left(\mathrm{a}+\mathrm{b}\left[\mathrm{H}^{+}\right]\right)\left[\mathrm{BPR}^{2-}\right]\left[\mathrm{NO}_{2}{ }^{-}\right]
$$

Added anions had no effect on the rate of the reaction (Table 2). Spectroscopic evidence and Michaelis - Mentens plot of $1 / \mathrm{k} 1$ versus $1 / \mathrm{IO}_{4}{ }^{-}$(Fig. 3) suggest the absence of an intermediate in the rate determining step. Free radical test did not yield gel formation. Based on the results obtained, this reaction is probably operating by the outersphere mechanism. 
Reaction Mechanism

$\mathrm{NO}_{2}^{-}+\mathrm{H}^{+} \stackrel{\mathrm{K}_{1}}{\rightleftharpoons} \mathrm{HONO}$

$\mathrm{HONO}+\mathrm{BPR}^{2-} \stackrel{\mathrm{k}_{2}}{\longrightarrow} \mathrm{BPR}^{3-}+\mathrm{HNO}_{2}{ }^{+}$

slow

$\mathrm{BPR}^{2-}+\mathrm{NO}_{2}^{-} \stackrel{\mathrm{k}_{3}}{\longrightarrow}$ Product

slow

Rate $=\mathrm{k}_{2}[\mathrm{HONO}]\left[\mathrm{BPR}^{2-}\right]+\mathrm{k}_{3}\left[\mathrm{BPR}^{2-}\right]\left[\mathrm{NO}_{2}{ }^{-}\right]$

From Eq. (5):

$[\mathrm{HONO}]=\mathrm{K}_{1}\left[\mathrm{NO}_{2}{ }^{-}\right]\left[\mathrm{H}^{+}\right]$

Substituting Eq. (9) into (8):

$$
\begin{aligned}
& \text { Rate }=\mathrm{k}_{3}\left[\mathrm{BPR}^{2-}\right]\left[\mathrm{NO}_{2}^{-}\right]+\mathrm{k}_{2} \mathrm{~K}_{1}\left[\mathrm{BPR}^{2-}\right]\left[\mathrm{NO}_{2}^{-}\right]\left[\mathrm{H}^{+}\right] \\
& \text {Rate }=\left(\mathrm{k}_{3}+\mathrm{k}_{2} \mathrm{~K}_{1}\left[\mathrm{H}^{+}\right]\right)\left[\mathrm{BPR}^{2-}\right]\left[\mathrm{NO}_{2}^{-}\right]
\end{aligned}
$$

Equation (11) is similar to Eq. (4)

where $a=k_{3}$ and $b=k_{2} K_{1}$

Table 1: Pseudo - first order and second order rate constants for the reaction of Bromopyrogallol

\begin{tabular}{|c|c|c|c|c|}
\hline $\begin{array}{l}10^{3}\left[\mathrm{NO}_{2}^{-}\right] \\
\mathrm{mol} \mathrm{dm}^{-3}\end{array}$ & $\begin{array}{l}10^{4}\left[\mathrm{H}^{+}\right] \\
\mathrm{mol} \mathrm{dm}\end{array}$ & $\begin{array}{c}10^{1}, \mathrm{I} \\
\mathrm{mol} \mathrm{dm}\end{array}$ & $\mathrm{s}^{-1} \mathbf{k}_{1}$, & $\underset{\mathrm{dm}^{3} \mathrm{~mol}^{-1} \mathrm{~s}^{-1}}{\mathrm{k}_{2}}$ \\
\hline 2.16 & 1.0 & 1.0 & 0.0932 & 43.16 \\
\hline 3.60 & 1.0 & 1.0 & 0.1566 & 43.50 \\
\hline 5.04 & 1.0 & 1.0 & 0.2179 & 43.62 \\
\hline 6.48 & 1.0 & 1.0 & 0.2687 & 43.62 \\
\hline 7.92 & 1.0 & 1.0 & 0.3487 & 44.03 \\
\hline 9.36 & 1.0 & 1.0 & 0.4058 & 43.34 \\
\hline 7.92 & 0.1 & 1.0 & 0.0800 & 10.10 \\
\hline 7.92 & 0.2 & 1.5 & 0.1259 & 15.99 \\
\hline 7.92 & 0.5 & 1.0 & 0.2000 & 25.19 \\
\hline 7.92 & 1.0 & 1.0 & 0.3802 & 48.01 \\
\hline 7.92 & 2.0 & 1.0 & 0.4000 & 50.71 \\
\hline 7.92 & 1.0 & 0.1 & 0.3483 & 43.97 \\
\hline 7.92 & 1.0 & 0.5 & 0.3455 & 43.63 \\
\hline 7.92 & 1.0 & 0.8 & 0.3429 & 43.29 \\
\hline 7.92 & 1.0 & 1.0 & 0.3366 & 43.49 \\
\hline 7.92 & 1.0 & 1.8 & 0.3488 & 43.97 \\
\hline 7.92 & 1.0 & 4.1 & 0.3455 & 43.62 \\
\hline
\end{tabular}
red and $\mathrm{NO}_{2}{ }^{-}$at $\left[\mathrm{BPR}^{2-}\right]=7.2 \times 10^{-5} \mathrm{~mol} \mathrm{dm}{ }^{-3}, \lambda \max =525 \mathrm{~nm}$ and $\mathrm{T}=29 \pm 1^{\circ} \mathrm{C}$ 
Table 2: Rate data for the effect of added anions $\left(\mathrm{Cl}^{-}\right.$and $\left.\mathrm{HCOO}^{-}\right)$on the rate of reaction of Bromopyrogallol red with $\mathrm{NO}_{2}^{-}$at $\left[\mathrm{BPR}^{2-}\right]=7.2 \times 10^{-5} \mathrm{~mol} \mathrm{dm}{ }^{-3},\left[\mathrm{NO}_{2}^{-}\right]=7.92 \times 10^{-3} \mathrm{~mol} \mathrm{dm}^{-3}$, $\left[\mathrm{H}^{+}\right]=1.0 \times 10^{-2} \mathrm{~mol} \mathrm{dm}^{-3}, \mathrm{I}=0.1 \mathrm{~mol} \mathrm{dm}^{-3}, \lambda \max =525 \mathrm{~nm}$ and $\mathrm{T}=29 \pm 1^{\circ} \mathrm{C}$

\begin{tabular}{llll}
\hline Ion & $10^{4}[$ ion], & $10^{3} \mathrm{k}_{1}$, & $\mathrm{K}_{2}$, \\
& $\mathrm{mol} \mathrm{dm}^{-3}$ & $\mathrm{~s}^{-1}$ & $\mathrm{dm}^{3} \mathrm{~mol}^{-1} \mathrm{~s}^{-1}$ \\
\hline
\end{tabular}

$\mathrm{Cl}^{-}$

10.0

0.3422

43.20

40.0

0.3322

42.00

80.0

0.3361

42.44

100.0

0.3391

42.81

200.0

0.3394

42.85

400.0

0.3391

42.81

$\mathrm{HCOO}^{-}$

10.0

0.3480

43.92

40.0

0.3455

43.62

80.0

0.3374

42.60

100.0

0.3445

42.62

200.0

0.3327

42.00

400.0

0.3426

43.26 


\section{$\log \left[\mathrm{NO}_{2}^{-}\right]$}

\begin{tabular}{llllllllll}
-2.9 & -2.8 & -2.7 & -2.6 & -2.5 & -2.4 & -2.3 & -2.2 & -2.1 & -0.2 \\
\hline
\end{tabular}

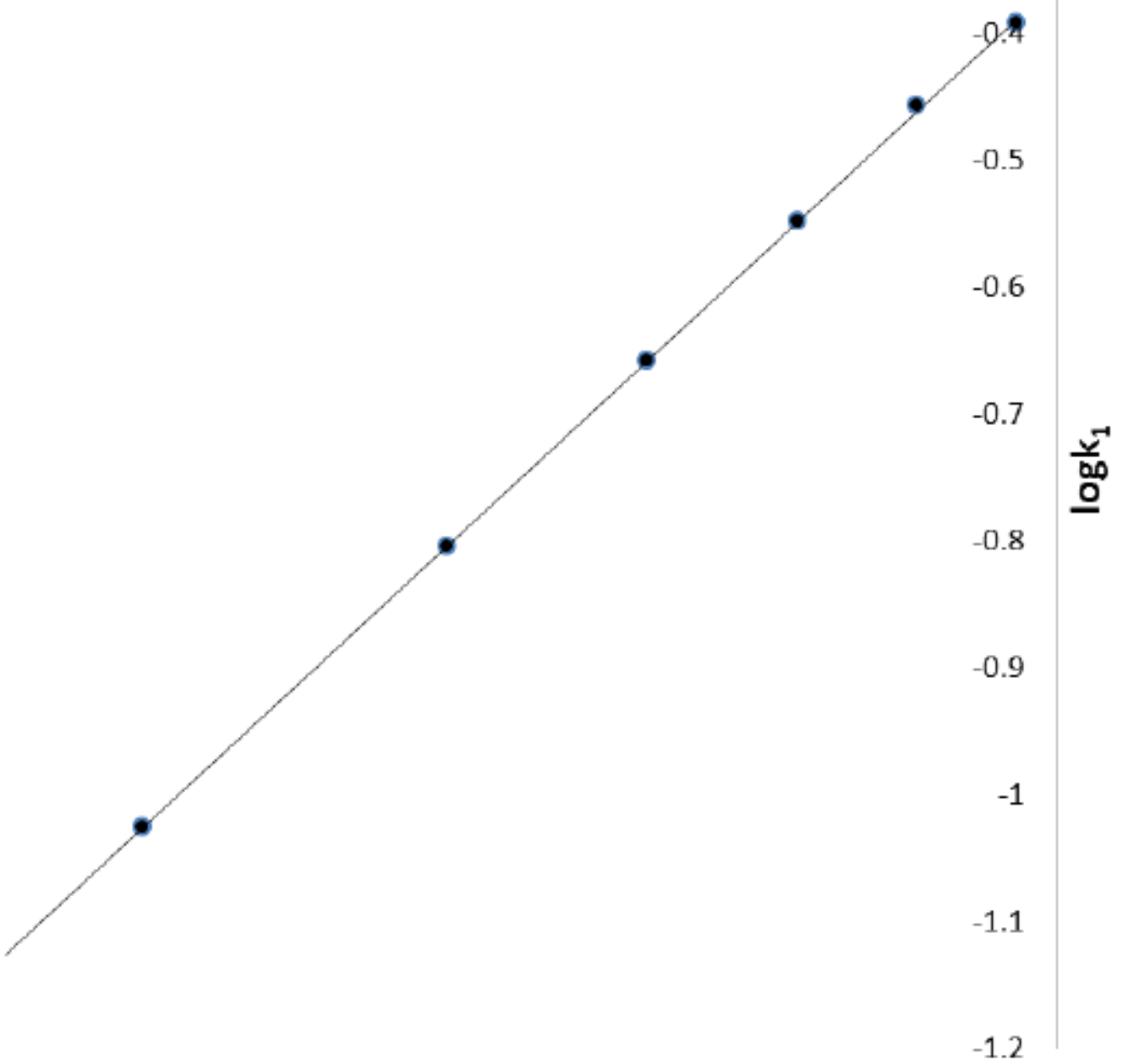

Figure 1: Plot of $\operatorname{logk} 1$ versus $\log \left[\mathrm{NO}_{2}^{-}\right]$for the redox reaction of bromopyrogallol red with nitrite ion at $\left[\mathrm{BPR}^{2-}\right]=7.2 \times 10^{-5} \mathrm{~mol} \mathrm{dm}{ }^{-3},\left[\mathrm{NO}_{2}^{-}\right]=(2.16-9.36) \times 10^{-3} \mathrm{~mol} \mathrm{dm}^{-3},\left[\mathrm{H}^{+}\right]=1.0 \times 10^{-4} \mathrm{~mol}$ $\mathrm{dm}-3, \mathrm{I}=0.1 \mathrm{~mol} \mathrm{dm}^{-3}, \lambda \max =525 \mathrm{~nm}$ and $\mathrm{T}=29 \pm 1^{\circ} \mathrm{C}$ 


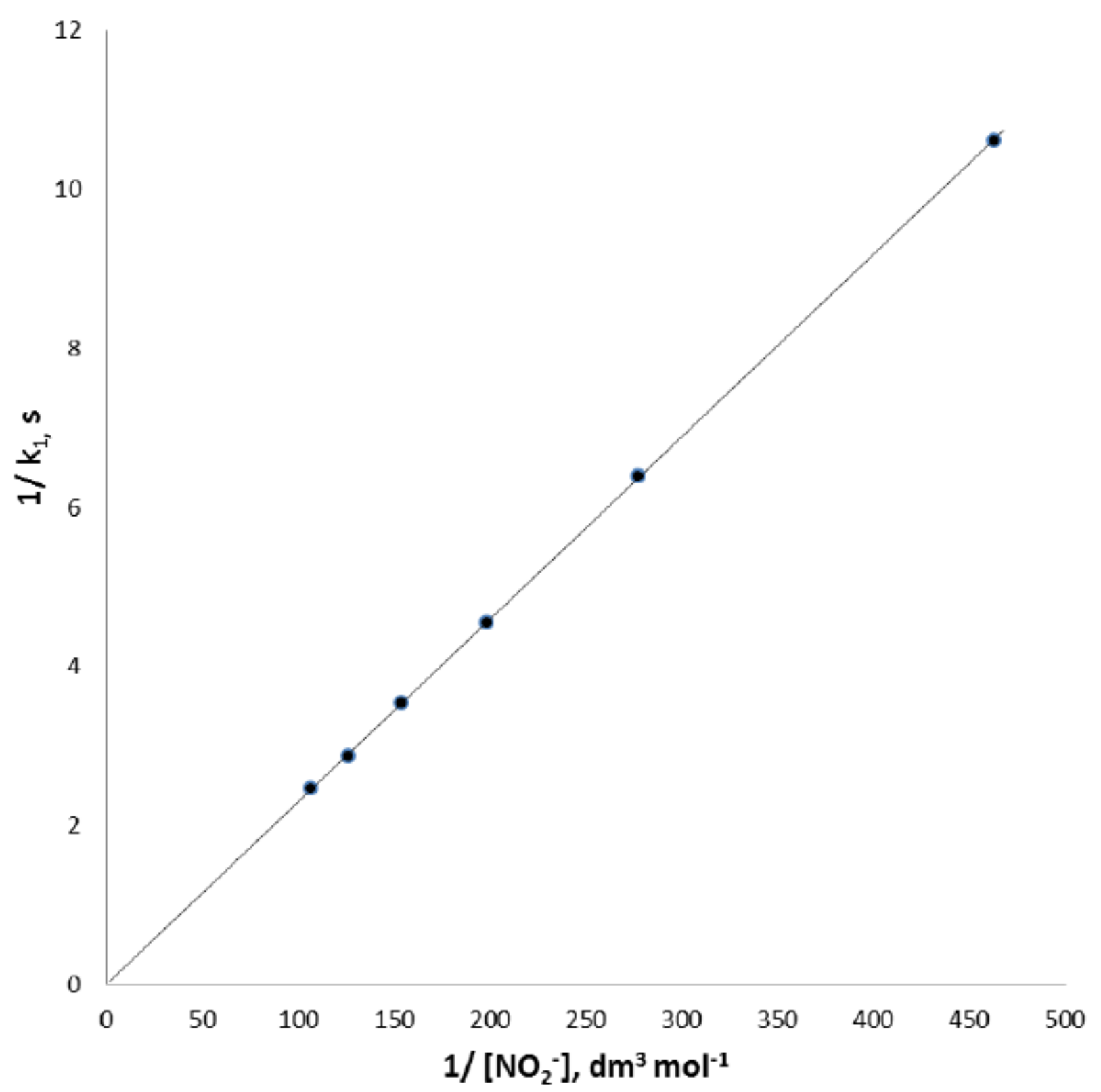

Figure 2: Michaelis - Menten plot for the redox reaction between Bromopyrogallol and $\mathrm{NO}^{-}$at $\left[\mathrm{BPR}^{2-}\right]=7.2 \times 10^{-5} \mathrm{~mol} \mathrm{dm}^{-3},\left[\mathrm{NO}_{2}{ }^{-}\right]=(2.16-9.36) \times 10^{-3} \mathrm{~mol} \mathrm{dm}^{-3},\left[\mathrm{H}^{+}\right]=1.0 \times 10^{-4} \mathrm{~mol} \mathrm{dm}^{-3}, \mathrm{I}$ $=0.1 \mathrm{~mol} \mathrm{dm}^{-3}, \lambda \max =525 \mathrm{~nm}$ and $\mathrm{T}=29 \pm 1^{\circ} \mathrm{C}$

\section{Conclusion}

The redox reaction of bromopyrogallol red and nitrite ion in aqueous acidic medium showed a stoichiometry of $1: 1$, a first order was observed for $\mathrm{BPR}^{2-}$ and $\mathrm{NO}_{2}^{-}$ion. The rate constant increases with increase in ionic strength. Spectroscopic evidence and Michaelis - Mentens plot of $1 / \mathrm{k} 1$ versus $1 / \mathrm{NO}_{2}{ }^{-}$suggests the absence of an intermediate in the rate determining step. Added anions had no effect on the rate of reaction. Based on the above results, it is proposed that the reaction operates probably through the outersphere mechanism. 


\section{References}

[1] A. Adetoro, J. F. Iyun and S. O. Idris. Kinetic Approach to the Mechanism of Redox Reaction of Pyrocatechol Violet and Nitrite Ion in Aqueous Hydrochloric Acid. Research Journal of Applied Sciences. Engineering and Technology 3(10): 1159-1163, 2011 and the references therein.

[2] Keihei, U., Toshiaki, I. and Chang, K. L. Handbook of organic and analytical reagents, 2nd ed. Boca Raton, CRC Press, 1992.

[3] Mohammed, Y., Iyun, J. F. and Idris, S. O. Kinetic approach to the mechanism of the redox reaction of malachite green and permanganate ion in aqueous acidic medium.Afr. J. Pure Appl. Chem., 2009, 3: 12, 269.

[4] Onu, A.D. and J.F. Iyun, 1998. Kinetics and mechanism for oxidation of rosaniline monochloride by nitrite ions. J. Chem. Res., 3: 25-26.

[5] Onu, A.D., Iyun, J. F. and Idris, S.O. The kinetics of the reduction of tetraoxoiodate(VII) by n(2-hydroxylethyl)ethylenediaminetriacetatocobaltate (II) ion in aqueous perchloric acid. Trans. Met. Chem., 2009, 34:849-853.

[6] Babatunde, O. (2009). Kinetics and mechanism of reduction of parafushin by nitrite ions in aqueous medium. World J. Chem., 4(1):39-44.

[7] Gupta, K.S. and Gupta, Y.K. (1984).Hydrogen ion dependence of reaction rates andmechanism.J. Chem. Edu., 61:11. 